\title{
Sarcopenia in chronic kidney disease - A brief review
}

\author{
Beatriz Donato $^{1}$ iD, Catarina Teixeira ${ }^{1}$ (iD), Sónia Velho² iD, Edgar Almeida ${ }^{1}$ iD \\ ${ }^{1}$ Nephrology Department, Hospital Beatriz Ângelo, Loures, Portugal. \\ 2 Nutricionist, Dietetics and Nutrition Department, Hospital Beatriz Ângelo, Loures, Portugal.
}

\section{ABSTRACT}

Sarcopenia is a progressive age-related loss of muscle mass associated with a decline in muscle function and physical performance. Patients with chronic kidney disease experience substantial loss of muscle mass, weakness, and poor physical performance. Indeed, with the progression of chronic kidney disease, skeletal muscle dysfunction contributes to mobility limitation, loss of functional independence, and vulnerability to disease complications.

There is a lack of robust data on the negative effect of the impact of kidney disease on skeletal muscle dysfunction, as well as on screening and treatment strategies that can be used in clinical practice to prevent functional decline and disability. Therefore, sarcopenia may be an underestimated condition with major implications for people with chronic kidney disease, even before the start of dialysis, which makes research into this topic necessary.

The purpose of this review is to expand on some fundamental topics of sarcopenia, with an emphasis on the setting of chronic kidney disease patients.

Keywords: Aging; Chronic Kidney Disease; Sarcopenia.

(C) 2021 Portuguese Journal of Nephrology \& Hypertension. Published by Publicações Ciência \& Vida This is an open access article under the CC BY-NC-ND license (http://creativecommons.org/licenses/by-nc-nd/4.0/).

\section{INTRODUCTION}

Sarcopenia is defined by the reduction of mass, strength, and muscle function. This chronic condition, associated with the physiological aging process, is common in patients with chronic kidney disease (CKD) from the early stages of the disease and the more severe the loss of renal function, the greater the risk of sarcopenia. ${ }^{1-3}$

The importance of maintaining muscle mass and physical and metabolic functions in the elderly is well-recognized. Progressive sarcopenia is ultimately central to the development of frailty, an increased likelihood of falls, and impairment of the ability to perform daily living activities. These alterations in muscle also play an important role in many diseases, such as CKD. ${ }^{4}$

Indeed, sarcopenia negatively affects skeletal muscle health in CKD, impairing the quality of life of these patients and contributing to morbidity and mortality. ${ }^{5}$ Therefore, early diagnosis and treatment of sarcopenia are crucial in all CKD patients to prevent the adverse outcomes related to this syndrome. These evaluations should be incorporated into pre-dialysis, peritoneal dialysis (PD), hemodialysis (HD), and kidney transplant patients. ${ }^{6}$

This article aims to review the impact of CKD on sarcopenia. We summarize general definitions of sarcopenia, its pathophysiology, clinical implications, as well as a diagnostic and therapeutic approach.

\section{DEFINITION AND PATHOPHYSIOLOGY OF SARCOPENIA}

The diagnosis of sarcopenia, developed by the European Working Group on Sarcopenia in Older People (EWGSOP), requires documentation of both low muscle mass and low muscle function (strength or performance). ${ }^{7}$ Pre-sarcopenia is defined as loss of skeletal muscle mass alone. ${ }^{8}$

There is another terminology for skeletal muscle loss conditions that must be differentiated from sarcopenia, including dynapenia, protein-energy wasting (PEW), frailty, and cachexia. Table I displays the definitions of these potentially confusing terms. This is particularly important for a practical approach as, for example, a patient who is diagnosed with sarcopenia will benefit from physical therapy to improve muscle mass and function, whereas a patient with PEW or cachexia will benefit from greater involvement of nutrition to combat the significant loss of muscle mass. ${ }^{9}$

Sarcopenia can be considered "primary" (or age-related) when no other cause is evident or "secondary" when causes are present, concomitant or not with aging. In the last category, besides activity-related sarcopenia (sedentary lifestyle) and nutrition-related sarcopenia (inadequate dietary intake of energy and/or protein, malabsorption conditions), the group of disease-related sarcopenia, such as CKD, is included. ${ }^{7}$ 


\section{Table I}

Terminology for skeletal muscle loss conditions, adapted from Moorthi RN et al ${ }^{9}$

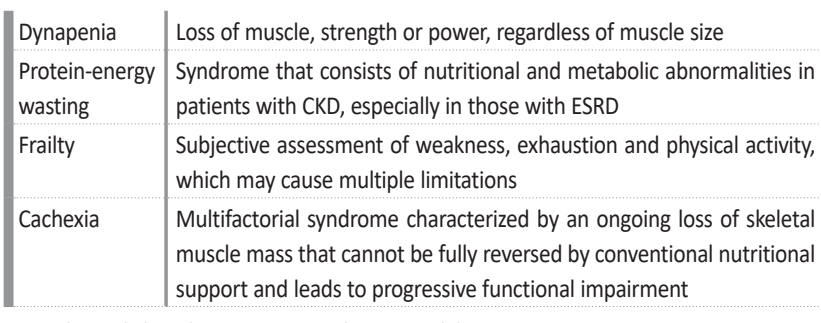

CKD - chronic kidney disease, ESRD - end-stage renal disease

With the increase in the world's older population, sarcopenia is becoming a major clinical problem in public health, and based on the results of a meta-analysis, the overall prevalence of sarcopenia is $10 \%{ }^{10}$

Several mechanisms are involved in the pathophysiology of sarcopenia, including age-related factors (mitochondrial dysfunction, apoptosis, atherosclerosis), hormonal imbalance (declines in serum testosterone and growth hormone $(\mathrm{GH})$ ), insulin resistance, immobility, neuromuscular integrity, changes in circulating pro-inflammatory cytokines, and muscle fat content. ${ }^{7}$ With aging, more phenomena lead to the development of sarcopenia. There is a progressive reduction in physical activity, increased body fatness, inflammation (increased cytokine levels), insulin resistance, nutritional deficiencies (protein, vitamin D, and other micronutrients), and reduced muscle protein synthesis. ${ }^{11}$

At the molecular level, sarcopenia may be a result of a disproportionate decrease in skeletal muscle protein synthesis and/or an increased protein breakdown. Proteolytic and lysosomal-dependent degradation, manipulated by myokines (such as myostatin and IL-6) may explain this relationship. Myostatin affects muscle wasting by disrupting skeletal muscle satellite cells and an up-regulation of E3 ligases instigating protein breakdown by the proteasome. IL-6 signaling, present in chronic systemic inflammation, has been associated with myogenesis. In CKD, these myokines are elevated, from the early stages. $^{5}$

Furthermore, elevated levels of angiotensin II stimulate caspase-3, which enhances actin cleavage, allowing actin and myosin to be degraded by the ubiquitin-proteasome system. Angiotensin II is also responsible for low circulating and skeletal IGF-1 levels, which enhances muscle wasting as well. This may explain the association of angiotensin converting enzyme inhibitors with increased muscle mass. ${ }^{11,12}$ In CKD, it has been also observed that FGF23 and Klotho induced muscle atrophy via reduction of insulin/IGF-I signaling. ${ }^{13}$

Also, there are understood factors directly related to muscle mass, strength, and function. Future studies may help to promote some beneficial interventions, including exercise and diet.

\section{METHODS TO EVALUATE SARCOPENIA}

Although sarcopenia has been emphasized as leading to dynapenia (muscle weakness), a more appropriate focus in sarcopenia includes the central function of muscle. As such, mobility is perhaps the best way to evaluate muscle impairments and serves as a primary indicator of functional ability. ${ }^{14}$

The measurable variables to evaluate sarcopenia are muscle mass, muscle strength, and physical performance, as illustrated in Table II. For clinical use, handgrip strength is a good simple measure of muscle strength and the short physical performance battery, including the usual gait speed, and the timed get-up-and-go test, can serve as performance measurements. ${ }^{7}$

Regarding muscle mass, there are some imaging methods for muscle mass assessment available. Computed tomography (CT) and magnetic resonance imaging (MRI) are considered gold standards to measure skeletal muscle mass in research. However, although these modalities allow precise evaluation of muscle mass, they are of limited availability, costly, time-consuming, and complex technologies. Dual $X$-ray absorptiometry (DXA) is the preferred alternative method for clinical use and currently the method used the most often to detect sarcopenia, as it requires less time and only a low radiation dose. In this method, the appendicular skeletal muscle mass (ASMM) analyses the sum of the muscle mass of the arms and legs and there is an ASMM index (the ratio between ASMM and height squared) cut-off for diagnosing sarcopenia in men and women. ${ }^{8}$

Bioimpedance analysis (BIA) estimates the volume of fat and lean body mass and it has also been proposed as a practical alternative to imaging modalities in multiple clinical settings. ${ }^{15}$ Equations to estimate skeletal muscle index by BIA have been proposed by the EWGSOP and are widely accepted screening tools for low muscle mass in the elderly population. $^{7}$

\section{SARCOPENIA IN CHRONIC KIDNEY DISEASE}

\section{Prevalence, risk factors and comorbidity}

There is a greater prevalence of secondary sarcopenia due to CKD than among subjects with normal renal function. The decline in muscle contributes to physical inactivity and multiple outcomes, even during the early stages of CKD. ${ }^{2,17-20}$ Table III summarizes the conclusions of some studies that have analyzed the prevalence of sarcopenia in CKD patients. The different findings suggest that there is not yet an agreement on which operational criteria to apply when diagnosing sarcopenia in CKD.

Skeletal muscle is considered the main source of protein in the body and protein is essential for antibody production, wound healing, and white blood cell production during acute or chronic illnesses. With the development of sarcopenia, the risk of disability and functional impairment is enhanced. It has been observed that HD patients with low lean mass and overhydration have significantly higher mortality. ${ }^{21}$ Furthermore, a study has proved that in patients with type 2 diabetes, the low muscle mass is independently associated with the increment of albuminuria, a surrogate marker of adverse renal and cardiovascular outcomes. ${ }^{22}$ In fact, the 


\section{Table II}

Methods available to evaluate sarcopenia, adapted from Sergi $G$ et al ${ }^{8}$, Sabatino et al ${ }^{16}$

\begin{tabular}{|c|c|c|c|}
\hline Technique & Measure variable in sarcopenia & Advantages & Disadvantages \\
\hline Anthropometry & Muscle mass & $\begin{array}{l}\text { Simple } \\
\text { Low cost } \\
\text { Widely available }\end{array}$ & $\begin{array}{l}\text { Low precision } \\
\text { Affected by hydration status } \\
\text { Need for high skilled anthropometrics }\end{array}$ \\
\hline $\begin{array}{l}\text { Bioelectrical } \\
\text { impedance }\end{array}$ & Muscle mass & $\begin{array}{l}\text { Simple } \\
\text { Low cost } \\
\text { Widely available } \\
\text { Information about nutritional and hydration status }\end{array}$ & $\begin{array}{l}\text { Affected by hydration status, body temperature, } \\
\text { nutrition, exercise } \\
\text { Not a direct measurement of lean mass }\end{array}$ \\
\hline $\begin{array}{l}\text { Physical } \\
\text { examination }\end{array}$ & $\begin{array}{l}\text { Muscle mass } \\
\text { Malnutrition-Inflammation Score and Subjective } \\
\text { Global Assessment }\end{array}$ & $\begin{array}{l}\text { Simple } \\
\text { No equipment } \\
\text { Information regarding nutritional status }\end{array}$ & $\begin{array}{l}\text { Not an objective measurement, not precise } \\
\text { Affected by hydration status }\end{array}$ \\
\hline $\begin{array}{l}\text { Dual X-ray } \\
\text { absorptiometry }\end{array}$ & $\begin{array}{l}\text { Muscle mass } \\
\text { Based on the attenuation of two X-ray beams with } \\
\text { different energy levels, it estimates bone mineral } \\
\text { density, fat mass and fat-free mass of the whole } \\
\text { body, or of specific anatomical regions }\end{array}$ & $\begin{array}{l}\text { Accurate quantitative estimate of skeletal muscle } \\
\text { mass } \\
\text { Low radiation dose }\end{array}$ & No information on quality changes in muscle mass \\
\hline $\begin{array}{l}\text { Computed } \\
\text { tomography }\end{array}$ & $\begin{array}{l}\text { Muscle mass } \\
\text { Produces cross-sectional scans enabling segmental } \\
\text { and total measures of fat and fat-free mass, based } \\
\text { on the average attenuation of the X-ray beam } \\
\text { through different body substrates }\end{array}$ & $\begin{array}{l}\text { Accurate quantitative and qualitative estimate of } \\
\text { skeletal muscle mass }\end{array}$ & $\begin{array}{l}\text { lonizing radiation } \\
\text { High cost and complexity (availability issue) }\end{array}$ \\
\hline $\begin{array}{l}\text { Magnetic } \\
\text { resonance imaging }\end{array}$ & $\begin{array}{l}\text { Muscle mass } \\
\text { Can estimate fat mas or fat-free mass and generate } \\
\text { cross-sectional images, by analyzing variations in } \\
\text { the radio frequency pulse sequence }\end{array}$ & $\begin{array}{l}\text { Accurate quantitative and qualitative estimate of } \\
\text { skeletal muscle mass } \\
\text { No ionizing radiation }\end{array}$ & High cost and complexity (availability issue) \\
\hline Ultrasound & $\begin{array}{l}\text { Muscle mass } \\
\text { Can estimate fat mas or fat-free mass and generate } \\
\text { cross-sectional images, by analyzing variations in } \\
\text { the radio frequency pulse sequence }\end{array}$ & $\begin{array}{l}\text { Quantitative and qualitative estimate of skeletal } \\
\text { muscle mass } \\
\text { Low-cost }\end{array}$ & Examiner-dependent \\
\hline Handgrip strength & Muscle strength & $\begin{array}{l}\text { Simple, easily performed } \\
\text { Portable } \\
\text { Low cost } \\
\text { Without contribution from the examiner }\end{array}$ & $\begin{array}{l}\text { May not represent strength in lower limbs/patients } \\
\text { with arthritis }\end{array}$ \\
\hline Chair stand test & Muscle strength & $\begin{array}{l}\text { Simple, easily performed } \\
\text { No equipment }\end{array}$ & Requires patient's collaboration \\
\hline Gait speed & Physical performance & $\begin{array}{l}\text { Simple, easily performed } \\
\text { No equipment }\end{array}$ & Requires large space \\
\hline $\begin{array}{l}\text { Short physical } \\
\text { performance } \\
\text { battery }\end{array}$ & $\begin{array}{l}\text { Physical performance } \\
\text { Combination of scores from balance, gait speed } \\
\text { and chair stand }\end{array}$ & $\begin{array}{l}\text { Simple, easily performed } \\
\text { No equipment }\end{array}$ & $\begin{array}{l}\text { Requires patient's collaboration } \\
\text { Requires large space }\end{array}$ \\
\hline $\begin{array}{l}\text { Timed get-up-and- } \\
\text {-go test }\end{array}$ & Physical performance & $\begin{array}{l}\text { Simple, easily performed } \\
\text { No equipment }\end{array}$ & $\begin{array}{l}\text { Requires large space } \\
\text { Cutoff points are not extensively validated }\end{array}$ \\
\hline
\end{tabular}

sarcopenia-related-CKD predisposes a patient to an increased risk of cardiovascular events. ${ }^{23}$

Multiple studies have already shown that nutritional disturbances are common in patients with CKD, with a predominance of sarcopenia and central obesity. ${ }^{24-28}$ In patients with CKD and obesity, the production of inflammatory mediators by adipose tissue also increase the prevalence of cardiovascular events. ${ }^{2}$

CKD patients manifest a phenotype of accelerated aging as a consequence of the several related risk factors (Table IV). Moreover, this is a 'chicken-or-egg' conundrum, as it is unknown whether reduced physical activity causes muscle loss or loss of muscle causes reduced activity. The loss of skeletal muscle may predispose to a more sedentary lifestyle, increased risk of falls and frailty with subsequently more fractures, hospitalizations, and poorer quality of life. ${ }^{29}$ Indeed, ameliorating physical function will improve the overall quality of life across the spectrum of CKD and this can be achieved by the implementation of exercise. ${ }^{5}$ Regular muscle mass assessment is strongly recommended in patients with CKD, regardless of the disease stage or the modality of renal replacement therapy. ${ }^{24}$ 


\section{Table III}

Prevalence of muscle loss conditions in chronic kidney disease.

\begin{tabular}{|c|c|c|c|}
\hline Author & \multicolumn{2}{|c|}{ Population } & Prevalence of sarcopenia \\
\hline Roshanravan et al, ${ }^{43} 2012$ & \multirow{5}{*}{ Non-dialysis-dependent patients } & 336 (stages 1-4 CKD) & $14 \%$ \\
\hline Kim et al, ${ }^{38} 2013$ & & 95 (all stages CKD) & $37 \%$ in men and $29.3 \%$ in women \\
\hline Pereira et al, ${ }^{25} 2015$ & & 287 (stages 3-5 CKD) & 5.9 to $9.8 \%$ \\
\hline Zhou et al, ${ }^{17} 2018$ & & 148 (stages 3-5 CKD) & $14 \%$ \\
\hline Moon et al, ${ }^{20} 2015$ & & 11625 (stages 2-5 CKD) & $6.3 \%$ (stage 2 CKD) and $15.4 \%$ (stage 3-5 CKD stage) \\
\hline Marini et al, ${ }^{44} 2018$ & \multirow{5}{*}{ Renal replacement therapy } & $62(\mathrm{HD})$ & $33 \%$ \\
\hline Isoyama et al, ${ }^{45} 2014$ & & $330(\mathrm{HD})$ & $20 \%$ \\
\hline Kamijo et al, ${ }^{32} 2018$ & & $119(P D)$ & $11 \%$ \\
\hline Abro et al, ${ }^{34} 2018$ & & 155 (PD) & $11-15.5 \%$ \\
\hline Yanishi et al, ${ }^{46} 2016$ & & 51 (Kidney transplant recipients) & $11.8 \%$ \\
\hline
\end{tabular}

CKD - chronic kidney disease, HD - hemodialysis; PD - peritoneal dialysis; ESRD - end-stage renal disease.

\section{$\underline{\text { Table IV }}$}

Risk factors for high prevalence of sarcopenia in chronic kidney disease patients

\section{Risk factors in CKD patients}

- Low physical inactivity

- Dietary restrictions with reduced protein intake

- Inflammation

- Aging

- Hormonal disorders (vitamin D deficiency, hyperparathyroidism, resistance to

growth hormone, resistance to insulin, increased angiotensin II)

- Metabolic disorders (metabolic acidosis, electrolyte disorder, uremic toxins

accumulation)

- Comorbidities (obesity, dementia, cardiovascular disease, diabetes, infections)

Muscle weakness in PD patients is frequent ${ }^{30}$ and associated with high inflammatory and nutritional markers. ${ }^{31}$ The associated poor outcomes, ${ }^{30}$ such as physical disability, decreased quality of life, increased morbidity, and a high mortality rate have also been demonstrated in several studies. ${ }^{32,33}$

Sarcopenia is even more common in HD patients. ${ }^{34}$ This subgroup of patients is more vulnerable to multiple metabolic and nutrition derangements, leading to changes in body composition, which can affect handgrip strength and muscle mass measurements. ${ }^{35,36}$ Published data showed that sarcopenia is a relatively common condition among patients undergoing maintenance $\mathrm{HD}$ and is associated with a worse survival rate. ${ }^{37,38}$

Kidney transplant recipients frequently also exhibit an abnormal body composition similar to sarcopenic obesity. ${ }^{39}$ Indeed, the impact of sarcopenia in transplant recipients is relevant. ${ }^{40}$ Patients who are sedentary, protein malnourished, and debilitated have been shown to experience increased mortality after many procedures, including vascular, oncologic, and transplant surgeries. ${ }^{41}$

To date, there are a limited number of studies that have examined the relationship between sarcopenia and decreased kidney function. ${ }^{20,25,26}$ In a systematic review and meta-analysis, sarcopenia was significantly associated with urinary protein level and decreased renal function, in patients with diabetes, although these analyses were performed using few studies. ${ }^{42}$

\section{Pathophysiology}

The pathogenesis of uremic muscle loss is complex and multifactorial and is still not fully understood. ${ }^{3,12,43}$ Several mechanisms are summarized in Figure 1, including the conditions of kidney disease itself, dialysis procedure, and typical chronic inflammation present in CKD. These conditions together lead to the dysregulation of the protein synthesis and catabolism, leading to a negative protein balance. ${ }^{16,47}$ Muscle wasting is characterized by increased muscle turnover rate and atrophy of type II muscle fibers. ${ }^{48}$ The final result is sarcopenia that progresses as CKD worsens. ${ }^{29}$

The kidney's non-inflammatory factors include hormonal imbalances, such as insulin resistance, decreased sex hormones levels, $\mathrm{GH}$ resistance, and vitamin D deficiency, and metabolic disorders such as metabolic acidosis. ${ }^{3}$

Impaired insulin signaling, involving the impact of low vitamin $D$ status, may be responsible for muscle proteolysis. ${ }^{49,50}$ Insulin is the main hormone responsible for muscle protein synthesis, and vitamin $D$ deficiency not only reduces pancreatic insulin secretion but also diminishes the stimulus for protein synthesis (by decreasing vitamin $D$ receptors present in muscle and reducing the calcium influx from cellular membranes). ${ }^{51}$ It is now evidenced that patients with sarcopenia and CKD may share insulin resistance and low vitamin D levels. ${ }^{20,48,50}$

Another phenomenon involved is the metabolic acidosis in CKD. Accumulation of acid in interstitial compartments, even before a fall in serum bicarbonate, can induce muscle damage and inflammation, produce or worsen bone disease, contribute to the progression of CKD and the development of hypoalbuminemia, increasing mortality. ${ }^{22,48}$

Other hormonal imbalances (low testosterone and GH resistance) are considered a potential cause of increased protein catabolism, by altering IGF-1 signaling. ${ }^{3}$ 


\section{Figure 1}

Pathophysiology of uremic sarcopenia, adapted from Souza VA et a ${ }^{3}$ and Sharma D et al. 27

\section{Uremic Sarcopenia}

\begin{tabular}{|c|c|}
\hline $\begin{array}{l}\text { Dialysis-related factors } \\
\text { - Loss of nutrients through the } \\
\text { dialysate } \\
\text { - Blood loss in the hemodialysis } \\
\text { machine } \\
\text { - Food restriction }\end{array}$ & $\begin{array}{l}\text { - } \downarrow \text { estrogen } \\
\text { - } \text { » energy expenditure } \\
\text { - Hypermetacocorticoid production } \\
\text { - } \text { 个 Angiotensin II } \\
\text { - Anemia (inadequate oxygen transport) }\end{array}$ \\
\hline \multirow{2}{*}{ 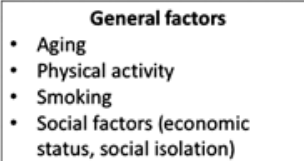 } & - Depression \\
\hline & $\begin{array}{l}\text { - Diabetes } \\
\text { - Cardiovascular disease } \\
\text { - Infections }\end{array}$ \\
\hline
\end{tabular}

Dialysis-related factors include the substantial loss of amino acids during the HD procedure and the reduced energy and protein intake. ${ }^{52}$

Inflammation conditions related to CKD have been demonstrated to be closely associated with sarcopenia, ${ }^{20,38}$ including early systemic markers of atherosclerosis and endothelial dysfunction such as reduction in high-density lipoprotein levels. ${ }^{18}$ For instance, fatty acid-binding protein 4, a novel adipokine primarily synthesized by adipocytes or macrophages that is expressed within human skeletal muscle fibers, has found to be an independent risk factor for sarcopenia in HD patients. ${ }^{53}$

The renin-angiotensin-aldosterone-system is highly activated in CKD and also seems to provide strong input to the development of uremic sarcopenia, as explained earlier. ${ }^{12}$

Indeed, the chronic inflammation in combination with sarcopenia induces anorexia and fat loss. ${ }^{20}$

CKD patients have altered cognitive function and mood that could be also associated with sarcopenia. Depression is one of the reasons for reduced appetite and hence for low energy/protein intake. ${ }^{18,38}$

Other risk factors for sarcopenia among CKD patients, such as drugs, should be investigated. One cross-section analysis revealed that in patients with pre-dialysis CKD patients, loop diuretic use was suggested to be a risk factor of sarcopenia. ${ }^{23}$

\section{Diagnosis}

For diagnostic purposes, skeletal muscle mass is the ideal target in the search for muscle abnormalities in CKD. The accuracy of all methods can be affected by CKD-related factors, especially hydration status. This is particularly important for methods that cannot distinguish between extracellular and intracellular fluid. ${ }^{54,55}$
Regarding imaging exams, CT has been studied in CKD patients undergoing $\mathrm{HD}^{56,57}$ and pre-dialysis patients ${ }^{58,59}$ as a measure of quantification of muscle mass and function.

Ultrasonography (US) was also demonstrated to be a valid and reliable method for evaluating the rectus femoris and cross-sectional area in patients in pre-dialysis CKD. ${ }^{60,61}$ This exam represents a valid potential alternative for identifying changes in muscle. ${ }^{8}$

ASMM, measured by DXA, is currently the most accepted method for muscle mass evaluation in CKD patients. ${ }^{8,55,62}$

Anthropometry estimates (which include mid-arm and calf circumference) and BIA are also widely available with low costs and are valid tools in CKD patients, however with lower precision. ${ }^{54}$

Finally, simplified screening scores for sarcopenia, using age, grip strength, and calf circumference have also been proposed, suggesting a potentially useful tool for estimating the future adverse event risk in patients with CKD. ${ }^{23}$

Among overweight or obese patients, the best way to assess and normalize skeletal muscle mass remains unclear. ${ }^{63}$

Table V summarizes some considerations about the diagnostic approach of sarcopenia in CKD patients, from the Kidney Disease Quality Initiative-National Kidney Foundation (KDOQI-NKF) guidelines. ${ }^{64}$ We think the choice of appropriate measures will depend on cost, clinical experience and the ease of each one. Beyond anthropometry, a physical exam (muscle wasting and palpation) and BIA, an imaging method to evaluate muscle mass may be considered (particularly those which are part of the clinical workup). However, other sarcopenia features may be more easily assessed and therefore applied, such as handgrip strength and gait speed.

\section{Table V}

Diagnostic approach of sarcopenia in chronic kidney disease, adapted from Ikizler T et al. ${ }^{64}$

Diagnostic approach to sarcopenia in chronic kidney disease Routine nutritional assessment (KDOQI-NKF guidelines)

CKD 3-5D or post transplantation: comprehensive nutrition assessment (appetite, history of dietary intake, body weight and body mass index, biochemical data, anthropometric measurements, and nutrition-focused physical findings) at least within the first 90 days of starting dialysis, annually, or when indicated by nutrition screening

\section{- Bioimpedance Impedance}

CKD 5D on HD: 30 minutes after HD session (minimize the impact of hydration status)

CKD 1-5 or CKD 5D on PD: insufficient evident to suggest

- Dual-Energy X-Ray Absorptiometry

CKD 1-5D or post transplantation: use when feasible

- Body Composition and Body Mass Index

CKD 5D: at the first visit and to monitor at least monthly

CKD 4-5 or post transplantation: at the first visit and to monitor at every 3 months

CKD 1-3: at the first visit and to monitor at every 6 months

CKD - chronic kidney disease; HD - hemodialysis; PD - peritoneal dialysis 
There is a need for not only simple techniques capable of monitoring changes in muscle size with disease progression but also appropriate cutoffs for CKD patients. In addition, we should make an effort to apply those available.

\section{Early interventions}

Once sarcopenia is identified, interventions should be immediately carried out and monitored by specialized exercise physiologists or other appropriately trained health professionals, and nutritionists. ${ }^{9}$

Reduced physical activity in sarcopenic subjects, compared to healthy subjects, has been reported, and low muscle mass may reduce ability to participate in physical activities. ${ }^{20}$ Therefore, physical activity from the early stages of CKD may have protective benefits against the loss of muscle mass.

The KDOQI-NKF clinical practice guidelines recommend that all dialysis patients should have their physical activity levels assessed and should be regularly encouraged by dialysis staff to increase their physical activity levels. ${ }^{65}$ Resistance training promotes muscle growth and strength, and theoretically, this may be considered to be the preferred type of exercise to promote physical function in the CKD population. ${ }^{16}$ Some studies have investigated various modalities of exercise in the CKD population, including patients undergoing $\mathrm{HD}^{66}$ and renal transplant recipients. ${ }^{67}$

Regarding nutrition, the 2020 updated practice guideline for nutrition in CKD from the KDOQI-NKF guidelines recommends a protein intake of 0.6-0-8 g/kg/day for stages 3-5 CKD and 1.0-1.2 g/kg/day for stage 5D CKD, with an energy intake of $30 \mathrm{kcal} / \mathrm{kg} /$ day. ${ }^{64}$ In the case of sarcopenia, it is reasonable to change the dietary scheme to recover the nutritional status.

Interventions to reverse sarcopenia usually include the use of energy and protein supplementation combined with physical exercise.

However, many promising pharmacological interventions for sarcopenia are currently under investigation. In HD patients, angiotensin II receptor blockade has been associated with preserved muscle strength ${ }^{68}$ and treatment with the androgenic steroid oxymetholone has been associated with an increase in fat-free mass and handgrip strength. ${ }^{69}$

Potential therapeutic strategies targeting specific toxins have also been proposed, such as indoxyl sulfate, a uremic toxin that accelerates skeletal muscle atrophy by inducing mitochondrial dysfunction. ${ }^{70,71}$

Another with promising results is the high-tone external muscle stimulation that could improve microcirculation and, through this mechanism, reduce kidney damage in elderly patients with CKD and severe muscle atrophy. ${ }^{72}$

\section{FINAL REMARKS}

Sarcopenia represents a devastating complication that not only contributes to a sedentary lifestyle and poor quality of life but also increases the incidence of cardiovascular complications, morbidity, and mortality. CKD is a progressive condition that adversely affects musculoskeletal health and the prevalence of CKD-sarcopenia is higher than it is in primary sarcopenia, especially in HD patients.

There is increasing interest in the early diagnosis of sarcopenia, considering the adverse complications of this underestimated condition. In our daily practice, methods and criteria to diagnose sarcopenia in our CKD patients should start to be routinely applied and followed by the implementation of therapeutic strategies that could have improved clinical outcomes.

In the future, better management of sarcopenic patients will be possible by identifying novel therapy pathways, through a better understanding of pathogenic mechanisms, by optimizing the tools to monitor the impact of therapy, and by addressing individual therapeutic approaches.

Disclosure of potential conflicts of interest: none declared.

\section{References}

1. Hernandez $\mathrm{H}$, Obamwonyi $\mathrm{G}$, Harris-Love M. Physical therapy considerations for chronic kidney disease and secondary sarcopenia. J Funct Morphol Kinesiol 2018:5(3):5.

2. Souza VA, Oliveira D, Barbosa $S$, et al. Sarcopenia in patients with chronic kidney disease not yet on dialysis: Analysis of the prevalence and associated factors. PLoS One 2017;12(4):1-13.

3. Souza VA, Oliveira D, Mansur HN, Fernandes NM, Bastos MG. Sarcopenia in chronic kidney disease. Bras Nefrol 2015;37(1):98-105

4. Wolfe R. The underappreciated role of muscle in health and disease. Am J Clin Nutr 2006;84: $475-82$.

5. Leal D, Ferreira A, Watson E, Wilung K, Viana J. Muscle-bone crosstalk in chronic kidney disease: the potential modulatory effects of exercise. Calcif Tissue Int 2021;108:461-75.

6. Musso CG, Jauregui JR, Núñez JF. Frailty phenotype and chronic kidney disease: a review of the literature. Int Urol Nephrol 2015;47(11):1801-7.

7. Cruz-Jentoft AJ, Baeyens JP, Bauer JM, et al. Sarcopenia: European consensus on definition and diagnosis: report of the European Working Group on Sarcopenia in Older People. Age Ageing 2010;39(4):412-23.

8. Sergi G, Trevisan C, Veronese N, Lucato P, Manzato E. Imaging in sarcopenia. Eur J Radiol 2016;85(8):1519-24.

9. Moorthi RN, Avin KG. Clinical relevance of sarcopenia in chronic kidney disease. Curr Opin Nephrol Hypertens 2017;26(3):219-28.

10. Shafiee G, Keshtkar A, Soltani A, Ahadi Z, Larijani B, Heshmat R. Prevalence of sarcopenia in the world: a systematic review and meta- analysis of general population studies. J Diabetes Metab Disord. 2017;16:21

11. Fielding RA, Vellas B, Evans WJ, et al. Sarcopenia: an undiagnosed condition in older adults. Current consensus definition: prevalence, etiology, and consequences. J Am Med Dir Assoc 2011;12: 249-56.

12. Stangl MK, Böcker W, Chubanov V, et al. Sarcopenia - Endocrinological and Neurological Aspects. Exp Clin Endocrinol Diabetes. 2019;127(1):8-22

13. Kido S, Hashimoto Y, Segawa H, Tatsumi S, Miyamoto K. Muscle atrophy in patients wirh ckd results from fgf23/klotho-mediated supression of insulin/igf-i signaling. Kidney Res Clin Prat. 2012;31: A16-196.

14. Roshanravan B, Gamboa J, Wilund K. Exercise and CKD: skeletal muscle dysfunction and practical application of exercise to prevent and treat physical impairments in CKD. Am J Kidney Dis 2017;69(6):837-52.

15. Chien MY, Huang TY, Wu YT. Prevalence of sarcopenia estimated using a bioelectrical impedance analysis prediction equation in community-dwelling elderly people in Taiwan. J Am Geriatr Soc 2008;56(9):1710-5.

16. Sabatino A, Cuppari L, Stenvinkel P, Lindholm B, Avesani C. Sarcopenia in chronic kidney disease: what have we learned so far? J Nephrol. 2020 (in press). doi: 10.1007/s40620-020-00840-y

17. Zhou Y, Hellberg M, Svensson P, Höglund P, Clyne N. Sarcopenia and relationships between muscle mass, measured glomerular filtration rate and physical function in patients with chronic kidney disease stages 3-5. Nephrol Dial Transplant. 2018;33(2):342-8.

18. Lai S, Muscaritoli M, Andreozzi P, et al. Sarcopenia and cardiovascular risk indices in patients with chronic kidney disease on conservative and replacement therapy. Nutrition 2019;62:108-14.

19. Tufan A, Tufan F, Akpinar T, Ilhan B, Bahat G, Karan M. Low glomerular filtration rate as an associated risk factor for sarcopenic muscle strength: is creatinine or cystatin C-based estimation more relevant? Aging Male 2017;20(2):110-4.

20. Moon SJ, Kim TH, Yoon SY, Chung JH, Hwang HJ. Relationship between stage of chronic kidney disease and sarcopenia in Korean aged 40 years and older using the Korea National Health and Nutrition Examination Surveys (KNHANES IV-2, 3, and V-1, 2) 2008-2011. PLoS One 2015;10(6). 
21. Hwang SD, Lee JH, Lee SW, Kim JK, Kim MJ, Song JH. Risk of overhydration and low lean tissue index as measured using a body composition monitor in patients on hemodialysis: a systemic review and meta-analysis. Re Fail 2018;40(1):51-9.

22. Chung HS, Hwang SY, Choi JH, et al. Effects of low muscle mass on albuminuria and chronic kidney disease in patients with type 2 diabetes: The Korean Sarcopenic Obesity Study (KSOS). Journals Gerontol - Ser A Biol Sci Med Sci. 2018;73(3):386-92.

23. Hanatani $S$, Izumiya $Y$, Onoue $Y$, et al. Non-invasive testing for sarcopenia predicts future cardiovascular events in patients with chronic kidney disease. Int J Cardiol 2018;268:216-21.

24. Dierkes J, Dahl H, Welland NL, et al. High rates of central obesity and sarcopenia in CKD irrespective of renal replacement therapy - An observational cross-sectional study. BMC Nephrology 2018;19(1):259.

25. Pereira RA, Cordeiro AC, Avesani CM, et al. Sarcopenia in chronic kidney disease on conservative therapy: prevalence and association with mortality. Nephrol Dial Transplant 2015;30(10):1718-25

26. D'alessandro C, Piccoli GB, Barsotti M, et al. Prevalence and correlates of sarcopenia among elderly CKD outpatients on tertiary care. Nutrients 2018;10(12):1-13.

27. Sharma D, Hawkins M, Abramowitz MK. Association of sarcopenia with egfr and misclassification of obesity in adults with CKD in the United States. Clin J Am Soc Nephrol 2014;9(12):2079-88.

28. Carrero JJ, Avesani CM. Pros and cons of body mass index as a nutritional and risk assessment tool in dialysis patients. Semin Dial 2015;28(1):48-58.

29. Avin KG, Moorthi R. Bone is not alone: the effects of skeletal muscle dysfunction in chronic kidney disease. Curr Osteoporos Rep 2015;13(3):173-9.

30. As'habi A, Najafi I, Tabibi H, Hedayati M. Prevalence of sarcopenia and dynapenia and their determinants in Iranian peritoneal dialysis patients. Iran J Kidney Dis 2018;12(1):53-60.

31. Lee MJ, Lee SA, Nam BY, et al. Irisin, a novel myokine is an independent predictor for sarcopenia and carotid atherosclerosis in dialysis patients. Atherosclerosis 2015;242(2):476-82.

32. Kamijo $Y$, Kanda E, Ishibashi $Y$, Yoshida M. Sarcopenia and frailty in PD: impact on mortality, malnutrition, and inflammation. Perit Dial Int 2018:38(6):447-54.

33. Jin S, Lu Q, Su C, Pang D, Wang T. Shortage of appendicular skeletal muscle is an independent risk factor for mortality in peritoneal dialysis patients. Perit Dial Int 2017;37(1):78-84.

34. Abro A, Delicata LA, Vongsanim S, Davenport A. Differences in the prevalence of sarcopenia in peritoneal dialysis patients using hand grip strength and appendicular lean mass: Depends upon guideline definitions. Eur J Clin Nutr 2018;72(7):993-9.

35. Camilleri S, Chong S, Tangvoraphonkchai K, Yoowannakul S, Davenport A. Effect of self-reported distress thermometer score on the maximal handgrip and pinch strength measurements in hemodialysis patients. Nutr Clin Pract 2017;32(5):682-6.

36. Garagarza G, Flores A, Valente A. Influence of body composition and nutrition parameters in handgrip strength: are there differences by sex in hemodialysis patients? Nutr Clin Pract 2017:33(2):247-54.

37. Rymarz A, Gibinska J, Zajbt M, Piechota W, Niemczyk S. Low lean tissue mass can be a predictor of one-year survival in hemodialysis patients. Ren Fail 2018;40(1):231-7.

38. Kim JK, Choi SR, Choi MJ, et al. Prevalence of and factors associated with sarcopenia in elderly patients with end-stage renal disease. Clin Nutr 2014;33(1):64-8.

39. Schütz T, Hudjetz H, Roske AE, et al. Weight gain in long-term survivors of kidney or liver transplantation-Another paradigm of sarcopenic obesity? Nutrition 2012;28(4):378-83.

40. Streja E, Molnar MZ, Kovesdy CP, et al. Associations of pretransplant weight and muscle mass with mortality in renal transplant recipients. Clin J Am Soc Nephrol 2011;6(6):1463-73.

41. Lentine KL, Axelrod D, Abbott KC. Interpreting body composition in kidney transplantation: weighing candidate selection, prognostication, and interventional strategies to optimize health. Clin J Am Soc Nephrol 2011;6(6):1238-40.

42. Satoshi I, Ryutaro K, Kanako I, Murata K. Association between sarcopenia and renal function in patients with diabetes: a systematic review and meta-analysis. J Diabetes Res 2019 (in press). doi: 10.1155/2019/1365189

43. Roshanravan $B$, Khatri $M$, Robinson-Cohen $\mathrm{C}$, et al. A prospective study of frailty in nephrology -referred patients with CKD. Am J Kidney Dis 2012;60(6):912-21.

44. Marini AC, Motobu RD, Freitas ATV, Laviano A, Pimentel GD. Pre-sarcopenia in patients undergoing hemodialysis: prevalence and association with biochemical parameters. Clin Nutr ESPEN 2018;28:236-8.

45. Isoyama N, Qureshi A, Avesani C, et al. Comparative associations of muscle mass and muscle strength with mortality in dialysis patients. Clin J Am Soc Nephrol 2014;9(10):1720-8.

46. Yanishia M,Kimura Y, Tsukaguchi H, et al. Factors related to osteosarcopenia in kidney transplant recipients. Transplant Proc 2018;50(10):3371-5.

47. Vliet S, Skinner S, Beals J, et al. Dysregulated handling of dietary protein and muscle protein synthesis after mixed-meal ingestion in maintenance hemodialysis patients. Kidney Int Rep 2018;3(6):1403-15.

48. Serpil $M$, Jennifer $R$, Jorge $G$, et al. Insulin resistance is a significant determinant of sarcopenia in advanced kidney disease. Am J Physiol Endocrinol Metab 2018;315(6):E1108-E20.

49. Hu Z, Wang H, Lee I, Du J, Mitch W. Endogenous glucocorticoids and impaired insulin signaling are both required to stimulate muscle wasting under pathophysiological conditions in mice. J Clin Invest 2009;119(10):3059-69.

50. Kim JE, Lee YH, Huh JH, Kang DR, Rhee Y, Lim SK. Early-stage chronic kidney disease, insulin resistance, and osteoporosis as risk factors of sarcopenia in aged population: The Fourth Korea National Health and Nutrition Examination Survey (KNHANES IV), 2008-2009. Osteoporos Int 2014;25(9):2189-98.
51. Molina P, Carrero J, Bover J, Chauveau P, Mazzaferro Sandro M, Torres P. Vitamin D, a modulator of musculoskeletal health inchronic kidney disease. J Cachexia Sarcopenia Muscle 2017;8(5):686-701.

52. Patrik D, Benoit L, Philippe L, Jambut-Cadon $D$, et al. Short-term effects of branched-chain amino acids-enriched dialysis fluid on branched-chain amino acids plasma level and mass balance: a randomized cross-over study. J Ren Nutr 2020;30(1):61-8.

53. Lin $\mathrm{YL}$, Liou HH, Lai YH, et al. Decreased serum fatty acid binding protein 4 concentrations are associated with sarcopenia in chronic hemodialysis patients. Clin Chim Acta 2018;485:113-8.

54. Carrero JJ, Johansen KL, Lindholm B, Stenvinkel P, Cuppari L, Avesani CM. Screening for muscle wasting and dysfunction in patients with chronic kidney disease. Kidney Int 2016;90(1):53-66.

55. Thomas J. Wilkinson. Identification of the most clinically useful skeletal muscle mass indices pertinent to sarcopenia and physical performance in chronic kidney disease. Nephrology; 2019 (in press). doi: https://doi.org/10.1111/nep.13678

56. McIntyre C, Selby N, Sigrist M, Pearce L, Mercer T, Naish P. Patients receiving maintenance dialysis have more severe functionally significant skeletal muscle wasting than patients with dialysis-indepen- dent chronic kidney disease. Nephrol Dial Transplant 2006;21:2210-6.

57. B Cheema, Abas H, Smith B, et al. Investigation of skeletal muscle quantity and quality in end-stage renal disease. Nephrology 2010;15(4):454-63.

58. Bichels A, Cordeiro A, Avesani C, et al. Muscle mass assessed by computed tomography at the third lumbar vertebra predicts patient survival in chronic kidney disease. J Ren Nutr 2020;27;S1051-2 (in press). doi: 10.1053/j.jrn.2020.05.007.

59. Giglio J, Kamimura M, Souza Net al. Muscle mass assessment by computed tomography in chronic kidney disease patients: agreement with surrogate methods. Eur J Clin Nutr 2019;73:46-53.

60. Souza VA de, Oliveira D, Cupolilo EN, et al. Rectus femoris muscle mass evaluation by ultrasound: facilitating sarcopenia diagnosis in pre-dialysis chronic kidney disease stages. Clinics (Sao Paulo) 2018;73(9):e392 (in press). doi: 10.6061/clinics/2018/e392

61. Gould D, Watson E, Wilkinson T, et al. Ultrasound assessment of muscle mass in response to exercise training in chronic kidney disease: a comparison with MRI. J Cachexia Sarcopenia Muscle 2019;10(4):748-55.

62. Hyun YY, Lee KB, Rhee EJ, Park CY, Chang Y, Ryu S. Chronic kidney disease and high eGFR according to body composition phenotype in adults with normal BMI. Nutr Metab Cardiovasc Dis 2016:26(12):1088-95.

63. Saitoh M, Ishida J, Springer J. Considering technique of assessment and method for normalizing skeletal muscle mass. J Cachexia Sarcopenia Muscle 2017;8(5):853-4.

64. Ikizler TA, Burrowes JD, Byham-Gray LD, et al. KDOQI nutrition in CKD guideline work group. KDOO clinical practice guideline for nutrition in CKD: 2020 update. Am J Kidney Dis 2020;6(3):S1-107.

65. Hanna RM, Ghobry L, Wassef O, Rhee CM, Kalantar-Zadeh K. A practical approach to nutrition, protein-energy wasting, sarcopenia, and cachexia in patients with chronic kidney disease. Blood Purif 2020;49(1-2):202-11.

66. Salhab N, Karavetian M, Kooman J, Fiaccadori, Khoury C. Effects of intradialytic aerobic exercise on hemodialysis patients: a systematic review and meta-analysis. J Nephrol 2019;32(4):549-66.

67. Calella P, Hernández-Sánchez S, Garofalo C, Ruiz J, Carrero J, Bellizzi V. Exercise training in kidney transplant recipients: a systematic review. J Nephrol 2019;32:567-79.

68. Lin Y, Chen S, Lai Y, Wang C, et al. Angiotensin II receptor blockade is associated with preserved muscle strength in chronic hemodialysis patients. BMC Nephrol 2019;20:54.

69. Supasyndh O, Satirapoj B, Aramwit P, et al. Effect of oral anabolic steroid on muscle strength and muscle growth in hemodialysis patients. Clin J Am Soc Nephrol 2013;8:271-79.

70. Yuki Enoki, Hiroshi W, Arake R, et al. Potential therapeutic interventions for chronic kidney disease-associated sarcopenia via indoxyl sulfate-induced mitochondrial dysfunction. J Cachexia Sarcopenia Muscle 2017;8(5):735-47.

71. Sato E, Mori T, Mishima E, et al. Metabolic alterations by indoxyl sulfate in skeletal muscle induce uremic sarcopenia in chronic kidney disease. Sci Rep 2016;6:1-13.

72. Di Micco L, Marzoco S, Adesso S, et al. Muscle stimulation in elderly patients with CKD and sarcopenia. Giornale Italiano di Nefrologia; 2015;32(5).

\section{ORCID}

Beatriz Donato (iD) 0000-0001-5264-0016

Catarina Teixeira (iD) 0000-0001-6860-5899

Sónia Velho (iD) 0000-0002-0879-9430

Edgar Almeida (iD 0000-0003-0702-4569

\section{Correspondence to:}

Beatriz Donato, MD

Nephrology department, Hospital Beatriz Ângelo, Loures, Portugal

E-mail: beatrizcamposdonato@gmail.com 